\title{
O INSTITUTO FEDERAL DE EDUCAÇÃO, CIÊNCIA E TECNOLOGIA DO RIO DE JANEIRO: VANTAGENS, DESVANTAGENS E PRIMEIROS DESAFIOS DA INSTITUIÇÃO
}

\author{
L. D. C. PAIVA*, N. M. P. SOUZA e C. R. OTRANTO \\ Universidade Federal Rural do Rio de Janeiro \\ lizdepaiva@yahoo.com.br*
}

Artigo submetido em outubro/2015 e aceito em dezembro/2015

DOI: $10.15628 /$ rbept.2016.3470

\section{RESUMO}

$\mathrm{O}$ artigo tem por objetivo caracterizar os desafios iniciais do Instituto Federal de Educação, Ciência e Tecnologia do Rio de Janeiro, que constitui um dos 38 Institutos Federais de Educação, Ciência e Tecnologia - IFs criados por meio da Lei 11.892/ 2008 (BRASIL, 2008). Esta lei instituiu ainda a Rede Federal de Educação Profissional, Científica e Tecnológica, promovendo novos contornos ao ensino técnico, tecnológico e profissional. Neste cenário, encontra-se ainda a Lei no. 13.0005/ 2014 (BRASIL, 2014) que aprova o Plano Nacional de Educação, evidenciando em sua Meta 11, dentre outros aspectos, o objetivo em triplicar as matrículas da educação profissional técnica de nível médio, pondo em relevo os Institutos, dada a sua amplitude territorial e suas particularidades. Neste estudo de natureza qualitativa, foram utilizadas pesquisas documentais e bibliográficas, além de pesquisa de campo. Para a apuração dos resultados foi empregada a análise de conteúdo, organizando os dados coletados por meio de categorias com unidades de contexto e de sentido.

PALAVRAS-CHAVE: Institutos Federais, IFRJ, PNE.

\section{THE INSTITUTE OF FEDERAL EDUCATION, SCIENCE AND TECHNOLOGY RIO DE JANEIRO: ADVANTAGES, DISADVANTAGES AND FIRST CHALLENGES OF THE INSTITUTION}

\begin{abstract}
The article aims to characterize the initial challenges of the Federal Institute of Education, Science and Technology of Rio de Janeiro, which is one of 38 Federal Institutes of Education, Science and Technology - IFs created by Law no. 11.892 / 2008 (BRAZIL, 2008). This law also established the Federal Professional Education Network, science and technology, promoting new dimensions to technical, technological and vocational education. In this scenario, it is still to Law no. 13.0005 /
\end{abstract}

2014 (BRAZIL, 2014) approving the National Education Plan, highlighting in its Target 11, among other things, the goal to triple the enrollment of mid-level technical professional education, emphasizing Institutes, given its amplitude land and its peculiarities. In this qualitative study, we used documentary and bibliographic research, and field research. For the determination of the results was used content analysis, organizing the data collected through categories with context units and meaning.

KEYWORDS: Federal Institute, IFRJ, PNE. 


\section{INTRODUÇÃO}

Esta pesquisa tem por objetivo caracterizar os desafios iniciais do Instituto Federal de Educação, Ciência e Tecnologia do Rio de Janeiro - IFRJ criado por meio de articulações políticas, resultando na Lei 11.892, de 29 de dezembro de 2008 (BRASIL, 2008).

A investigação foi embasada pelo contexto histórico vivenciado pela instituição recémcriada, o IFRJ, gerando um arcabouço de informações que por sua relevância aos estudos da expansão da Rede Federal se justificam na socialização dos relatos empíricos e dos estudos documentais alcançados.

A trajetória metodológica adotada neste estudo de abordagem qualitativa e exploratória foi composta de pesquisas documental e bibliográfica, proporcionando o aporte teórico na elaboração do problema e tornando possível o entendimento histórico em que a temática se inseria. Foram utilizadas ainda nesta investigação, observações de campo e entrevistas semiestruturadas com testemunhas-chave1, compostas por indivíduos nas funções de Gestores, Professores e Servidores Administrativos. Compôs também a amostra, os participantes das últimas Comissões Próprias de Avaliação - CPAs e ou membros que fizeram parte da Comissão de elaboração do Plano de Desenvolvimento Institucional - PDI (2009-2013) da instituição.

As entrevistas gravadas e devidamente autorizadas pelos dez respondentes selecionados geraram um montante de depoimentos em torno de 9 h e 30 minutos, realizados no período de julho a dezembro de 2011.

A técnica escolhida para a análise destas informações foi a Análise de Conteúdo apoiada em Bardin (1979). Esta opção foi determinante para o estabelecimento de critérios feitos por meio da identificação dos núcleos de sentido que fazem parte da comunicação. Foram, então, criadas categorias motivadas pela diversidade dos conteúdos apresentados pelos informantes. Tais categorias expressaram as percepções, as opiniões, os conceitos e as declarações dos entrevistados que versaram na primeira categoria sobre: a "transformação das Instituições de ensino em IFRJ".

Esta categoria possibilitou uma incursão na realidade do IFRJ de modo a buscar apreender suas experiências e práticas educacionais, o que resultou no testemunho dos depoentes quanto ao seu surgimento. As instituições de ensino que compuseram o IFRJ foram: o Centro Federal de Educação Tecnológica de Química de Nilópolis - RJ - CEFET de Química de Nilópolis/RJ e o Colégio Agrícola Nilo Peçanha - CANP então vinculado à Universidade Federal Fluminense-UFF. Esta temática foi a inspiração central para elaboração deste artigo, que buscou caracterizar os primeiros passos da trajetória sócio educacional do IFRJ e apontar seus primeiros desafios.

\section{NA TRILHA DA REDE FEDERAL}

O advento do ensino técnico profissional no Brasil foi marcado pelo contexto do Império, seguido da Primeira República (1889 - 1930) quando já figuravam indícios do capitalismo liberal, movido pelos intentos de expansões produtivistas praticados por países europeus.

\footnotetext{
${ }^{1}$ Trata-se de "pessoas que dispõem de notável conhecimento acerca da cultura do grupo, organização ou comunidade que está sendo estudada. O informante não precisa ser um membro proeminente do grupo. Pode ser até mesmo uma pessoa que por qualquer razão dele já tenha se afastado". (GIL, 2010, p. 128).
} 
Com o predomínio dos Organismos Multilaterais suscitaram diversas reformas educacionais, de modo a ajustar-se ao sistema produtivista. Houve então ao longo do tempo a criação de diversas instituições de ensino, dentre elas: as Escolas de Aprendizes e Artífices; os Liceus Industriais; as Escolas Industriais e Técnicas; as Escolas Técnicas Federais; as Escolas Agrotécnicas Federais; as Escolas Técnicas Vinculadas às Universidades Federais e os Centros Federais de Educação Tecnológica (CEFETs).

Dentre as constantes intervenções na educação profissional no Brasil tiveram como ponto de relevo o Decreto no 6.095/2007, (BRASIL, 2007) que apresentou o delineamento das diretrizes para a criação dos Institutos Federais de Educação, Ciência e Tecnologia - IFs, no âmbito da Rede Federal.

O instrumento utilizado para operacionalizar a referida criação foi a Chamada Pública MEC/SETEC ${ }^{2}$ n.o 002 em 12 de dezembro de 2007 que definiu os trâmites, bem como as instituições de ensino que poderiam fazer parte da composição dos IFs.

O cenário do sistema de produção no Rio de Janeiro, a exemplo de outros Estados do país, também exigia rápidas respostas às demandas empresariais. O CEFET de Química de Nilópolis/RJ, prontamente apresentava-se de acordo com a proposta governamental, conforme consta no seu Relatório da Comissão Própria de Avaliação - CPA ciclo 2006-2008.

Tinha-se então um cenário turbulento, pois, de acordo com Otranto (2011) o governo federal deu continuidade ao seu propósito de criação dos IFs por meio do Projeto de Lei 3.775/2008 apresentando uma nova estrutura para a Rede Federal. No findar do ano de 2008, mesmo sem a realização de uma ampla discussão no segmento acadêmico do país, teve-se a aprovação do projeto, fazendo surgir mais uma instituição de ensino, completamente distinta das então existentes, por meio da Lei 11.892/2008, (BRASIL, 2008) os IFs $^{3}$.

A estrutura da Rede Federal foi constituída na época pelas seguintes instituições: IFs; Universidade Tecnológica Federal do Paraná - UTFPR; Centros Federais de Educação Tecnológica Celso Suckow da Fonseca - CEFET-RJ e de Minas Gerais - CEFET-MG e Escolas Técnicas Vinculadas às Universidades Federais ${ }^{4}$.

\section{A COMPOSIÇÃO DO IFRJ}

Após a breve contextualização histórica da Rede Federal, tem-se um exemplar da política educacional empreendida pelo governo brasileiro. Trata-se do IFRJ, cujas características originais, têm sofrido significativas transformações.

O IFRJ tem sua origem na criação do Curso Técnico de Química Industrial - CTQI por meio do Decreto-Lei no. 8.300/1945, (BRASIL, 1945). Com o advento das ações de governo, o CTQI assumiu status de autarquia tornando-se Escola Técnica de Química (ETQ) e logo em seguida Escola

\footnotetext{
${ }^{2}$ Secretaria de Educação Profissional e Tecnológica do Ministério da Educação.

${ }^{3}$ Em seu Art. 2o, a lei define que: “Os Institutos Federais são instituições de educação superior, básica e profissional, pluricurriculares e multicampi, especializados na oferta de educação profissional e tecnológica nas diferentes modalidades de ensino, com base na conjugação de conhecimentos técnicos e tecnológicos com as suas práticas pedagógicas $[\ldots]^{\prime \prime}$.

${ }^{4}$ O Colégio Pedro II foi incorporado à Rede Federal por meio da Lei no 12.677 , de 25/6/2012, em seu art 5ㅇ.
} 
Técnica Federal de Química (ETFQ). Em 1985 a ETFQ passa a chamar-se Escola Técnica Federal de Química do Rio de Janeiro (ETFQ-RJ).

A ETFQ-RJ expandiu-se ainda mais com a criação da Unidade de Ensino Descentralizada (UNED) no município de Nilópolis no Estado do Rio de Janeiro, na década de 1990, com o oferecimento dos cursos Técnicos de Química e de Saneamento.

Em 1994 a ETFQ-RJ tornou-se Centro Federal de Educação Tecnológica de Química de Nilópolis-RJ no ano de 1999. A mudança da sede da ETFQ-RJ até então localizada no Maracanã para a UNED da ETFQ-RJ em Nilópolis repercutiu nas estruturas administrativas, políticas e educacionais, bem como nos aspectos culturais e de identidade institucional.

Em 2001 o CEFET de Química de Nilópolis/RJ deu início aos cursos de graduação e pósgraduação, marcando assim o advento da verticalização5 na instituição.

O CEFET de Química de Nilópolis/RJ oferecia além do ensino médio, os cursos técnicos: Química; Alimentos; Biotecnologia; Controle Ambiental; Laboratório de Farmácia; Meio Ambiente e Metrologia. Somavam-se também os cursos superiores: Tecnologia em Produção Cultural; Tecnologia em Processos Industriais; Tecnologia em Química de Produtos, assim como as Licenciaturas em Química e Física.

Quanto ao Colégio Agrícola Nilo Peçanha - CANP6 destacam-se a vocação agropecuária da região de Pinheiral e o fato do Colégio ter sido o Patronato Agrícola e Aprendizado Agrícola Nilo Peçanha, com marcante inserção rural. Com a Lei no. 11.892/2008, o CEFET de Química de Nilópolis/RJ composto de suas unidades somou-se ao Colégio Agrícola Nilo Peçanha - CANP, formando o IFRJ.

\section{OS INFORMANTES-CHAVE E O IFRJ: PERCEPÇÕES}

Os informantes-chave transmitiram dados e informações acerca do contexto de transformação institucional em que se encontravam inseridos. A questão pertinente à contextualização histórica foi representada pelos seguintes núcleos de sentido: O processo de transformação da instituição em IFRJ. Vantagens, desvantagens ou o desconhecimento sobre o processo.

A classificação de vantagem inserida na questão teve o sentido de possibilidade de ganho, de benefício, de algo considerado próspero. Diferente do entendimento de desvantagem que figurou à condição de perda, de retrocesso, de malefício frente à gênese contextual. As respostas ganharam relevo em função de suas diversidade e importância sendo necessário configurar dois eixos de análise que contemplassem os conteúdos das falas com especificidades mais apuradas, foram eles: Estruturas física, organizacional e legal; cultura e identidade.

No tocante ao primeiro eixo: Estruturas física, organizacional e legal, verificou-se que a verticalização conferida aos Institutos Federais pela Lei 11.892/2008 no Art. 60, inciso III “promover

\footnotetext{
${ }^{5}$ A Lei no 11.892/ 2008 em seu art. 6․ inciso III afirma que a verticalização se constitui em uma das finalidades e características dos Institutos Federais, quando são contempladas pela instituição as dimensões da educação básica à educação profissional e educação superior.

${ }^{6}$ Ao longo de sua existência o CANP, teve várias designações. A instituição ofertava cursos técnicos e supletivos nas áreas de zootecnia, veterinária e agroindústria.
} 
a integração e a verticalização da educação básica à educação profissional e educação superior, otimizando a infraestrutura física, os quadros de pessoal e os recursos de gestão", despertou opiniões divergentes.

Uma opinião contrária foi exposta por um dos respondentes, ao afirmar que a estrutura verticalizada é híbrida, dificultando a prática do processo de ensino-aprendizagem, em função das exigências pedagógicas de cada nível de ensino pertinentes à diversidade dos alunos, bem como os processos operacionais inerentes a cada segmento escolar. Tais dificuldades somavam-se à necessidade de adaptação do docente em adquirir e ou desenvolver uma polivalência pedagógica, assim como ambientar-se às particularidades da instituição de ensino e de seu entorno. O docente, no caso, estava se referindo à verticalização do trabalho do professor que, na estrutura dos IFs lecionam em vários níveis e modalidades.

Como desvantagens podem ser elencadas ainda, o fato do Campus Rio de Janeiro por sua estrutura administrativa e de pessoal consolidada como antiga ETFQ-RJ enquanto unidade matriz tornou-se unidade do CEFET de Química de Nilópolis e com o advento dos IFs manteve-se como unidade de Campus. Assim, o Campus Rio de Janeiro foi constantemente requisitado para ceder servidores aos quadros dos novos campi, desfalcando de certa forma o planejamento organizacional da unidade.

Contudo, tais embaraços pareceram perder força no discurso de alguns respondentes na medida em que as ações vantajosas foram sendo praticadas no cotidiano acadêmico, postergando a tratativa das questões conflituosas que emergem da lei de criação dos IFS. Dentre tais ações, a maioria dos entrevistados apontou a interiorização dos campi, ofertando a municípios e regiões do Rio de Janeiro, unidades de ensino público de qualidade, proporcionando número maior de vagas ao alunado.

Foram apontadas ainda como favoráveis à implantação, de acordo com as determinações da Lei 11.892/2008 em seu Art. 70, inciso VI, alínea b, que confere aos IFs dentre seus objetivos, oferecer cursos de educação superior, bem como o Art. 8 que define o mínimo de $20 \%$ (vinte por cento) de suas vagas para os cursos de licenciatura.

Cabe ressaltar que o CEFET de Química de Nilópolis/RJ possuía desde 2002 experiências no oferecimento de Cursos Superiores de Tecnologia e Licenciaturas em Química e Física a partir de 2003. Somaram-se ainda, os cursos de Pós-Graduação Lato Sensu criados em 2005. Tais vivências acadêmicas podem ter contribuído como facilitadoras diante das determinações legais, o que não isentou a instituição de se deparar com a complexidade imposta com a nova configuração institucional.

Os respondentes apontaram também como vantajosa, a equiparação dos IFs às Universidades Federais no tocante à pesquisa. Argumentaram que apesar do CEFET de Química de Nilópolis/RJ possuir iniciativas científicas, as oportunidades de apoio por meio dos órgãos oficiais de fomento eram restritas. Tal fato evidenciou a continuidade de uma prática já realizada pelas instituições que compuseram o IFRJ, que consistia na conexão da Instituição com o desenvolvimento dos arranjos produtivos locais e que teve o seu fortalecimento com a Lei $n$ 으 11.892/2008 no Art. 60, inciso IV. 
No entanto, mesmo diante destes fatos elencados pelos respondentes como vantajosos, alguns outros pontos foram descritos como desvantajosos, gerando críticas e observações quanto à transformação e o crescimento acelerado da Rede Federal.

Diante da criação dos IFs, as instituições que o compuseram precisaram se ajustar à nova organização institucional, composta de uma estrutura acadêmica de complexidade similar às universidades federais, no que diz respeito à obrigatoriedade de amparo ao tripé ensino, pesquisa e extensão. Com estas mudanças estruturais institucionais figurou-se uma nova dinâmica Cultural e de Identidade, formando nesta investigação, o segundo eixo de análise.

As experiências culturais adquiridas pela comunidade acadêmica oriundas do CEFET de Química de Nilópolis/RJ, composto por unidades com especificidades particulares, somaram-se ao centenário Colégio Agrícola Nilo Peçanha - CANP pertencente à UFF resultando em uma multiplicidade de identidades e culturas.

Percebeu-se nas falas dos informantes, a nostálgica lembrança da identidade técnica construída desde a década de 1940 também com significativas mudanças de rumo, porém bem distinta do perfil institucional traçado pela Lei no 11.892/2008, Art. 2‥ § 1ㅇ (BRASIL, 2008) quando equipara os IFs às Universidades Federais, no que tange aos pressupostos da regulação, avaliação e supervisão da instituição e dos cursos de educação superior.

Diante de tais relatos, percebeu-se como uma das desvantagens a perda da identidade das instituições tradicionais que deram origem ao IFRJ, tanto do CEFET de Química de Nilópolis/RJ, quanto do Colégio Agrícola Nilo Peçanha - CANP, evidenciando assim, a dificuldade na construção da identidade institucional do IFRJ.

Destaca-se que outra medida da lei valorizada pelos respondentes foi a proferida pelo Art. 70 ao delimitar o mínimo de $50 \%$ (cinquenta por cento) de suas vagas para a educação profissional técnica de nível médio. (BRASIL, 2008).

A criação da nova instituição apresentou conflitos ainda com a aquisição de novos docentes e profissionais administrativos, pois estes apresentavam em sua maioria uma significativa capacidade acadêmica, porém desconectados das origens daqueles que haviam vivenciado experiências no segmento técnico. Com raras exceções o perfil de docentes era desprovido de vivência nos ensinos médio e técnico, o que resultou em queda na qualidade do ensino, pois a velocidade na saída de professores experientes não pode ser compensada com a entrada de servidores estranhos às origens da instituição. Contudo, os respondentes também assinalaram para aspectos favoráveis quanto ao ingresso de profissionais administrativos, pois atestaram ser notória a contribuição dos mesmos nas discussões acadêmicas e administrativas, oferecendo uma "revitalização" de ideias e fazendo surgir um novo perfil do segmento.

A estrutura física e geográfica do IFRJ também representou dificuldades, haja vista que o sistema de comunicação já se mostrava falho na antiga configuração, agravando-se com o distanciamento dos campi. Os respondentes acenaram para investimentos em ferramentas tecnológicas no segmento de comunicação interna, mas, além disto, se fazia necessária a construção de uma cultura institucional que promovesse o compartilhamento de ideias.

As percepções dos respondentes apontadas no cenário de criação do IFRJ propiciaram parte do embasamento para entender os aspectos históricos que influenciaram o processo de transformação do IFRJ. 


\section{O IFRJ E A EDUCAÇÃO PROFISSIONAL TÉCNICA DE NÍVEL MÉDIO: O QUE DIZ O PNE?}

O contexto e espectro do surgimento dos IFs se ampliam com a Lei $\mathrm{n} N$. 13.0005, de junho de 2014 (BRASIL, 2008) que aprova o Plano Nacional de Educação - PNE. Neste documento são definidas as diretrizes do Plano, com destaque para o art. 2․ inciso $\vee$ que trata da "formação para o trabalho e para a cidadania, com ênfase nos valores morais e éticos em que se fundamenta a sociedade". Soma-se o inciso VII da referida lei ao tratar da "promoção humanística, científica, cultural e tecnológica do País".

Cabe destacar que dadas às características dos IFs em se constituírem como instituições de educação superior, básica e profissional, especializados na oferta de educação profissional e tecnológica nas diferentes modalidades de ensino, estas instituições precisam se organizar de modo a atender as 20 metas do PNE, inclusive a meta 11 que diz:

Meta 11: triplicar as matrículas da educação profissional técnica de nível médio, assegurando a qualidade da oferta e pelo menos $50 \%$ (cinquenta por cento) da expansão no segmento público.

\section{Estratégias:}

11.1) expandir as matrículas de educação profissional técnica de nível médio na Rede Federal de Educação Profissional, Científica e Tecnológica, levando em consideração a responsabilidade dos Institutos na ordenação territorial, sua vinculação com arranjos produtivos, sociais e culturais locais e regionais, bem como a interiorização da educação profissional; (BRASIL, 2014).

Dentre as 20 metas do PNE, a meta 11 trata mais explicitamente da educação profissional, delegando aos Institutos a responsabilidade pelo seu alcance tendo em vista a sua interiorização e amplitude no território brasileiro.

Desta forma, os 38 IFs incluindo o IFRJ encontram-se diante de mais um desafio evidenciado pelo $\mathrm{PNE}$, que em referência à verticalização do ensino prevista na Lei 11.892/2008 (BRASIL, 2008) contribui para a complexificação estrutural e conjuntural desta nova instituição de ensino e sua comunidade acadêmica.

\section{CONSIDERAÇÕES FINAIS}

Com base no objetivo desta pesquisa que se consistiu em caracterizar os desafios iniciais do IFRJ em sua nova configuração institucional, os resultados revelaram uma contextualização sócio educacional marcada por vantagens e desvantagens.

Os resultados deste estudo mostraram-se relevantes para a reflexão quanto aos efeitos da expansão da Rede Federal e, mais particularmente, da Lei 11.892/2008, que irradiou no ensino técnico, tecnológico e profissional particularidades inerentes à verticalização de ensino, assim como a equiparação dos IFs às Universidades Federais, no tocante a regulação, avaliação e supervisão das instituições e dos cursos superiores. 
Com isto, adentrar no lócus da investigação permitiu identificar e conhecer os informanteschave, que propiciaram uma multiplicidade de saberes, de culturas, de formações políticas e ideológicas próprias de uma instituição de ensino. Neste particular, percebeu-se o comprometimento dos pesquisados com a qualidade do ensino e com a formação dos alunos para a inserção no mundo do trabalho, destacando o papel integrador da instituição de ensino com a comunidade do seu entorno.

Assim sendo, houve a constatação da existência de diferentes "mundos" presentes nas unidades então pertencentes ao CEFET de Química de Nilópolis/RJ e ao Colégio Agrícola Nilo Peçanha - CANP, subordinado à Universidade Federal Fluminense, os quais compuseram o IFRJ.

A acelerada transformação do IFRJ gerou diferentes percepções e opiniões dos atores envolvidos, demonstrando a complexidade deste processo. Para alguns dos depoentes a transformação foi vantajosa em alguns pontos e desvantajosa em outros. Em determinados aspectos o termo desvantagem ganhou uma relativização com o sentido de problema transitório pertinente à transformação. A contradição se evidencia nas falas capturadas ora a favor, ora contra as ações estabelecidas tanto no âmbito governamental quanto nas instâncias internas e de gestão do IFRJ.

Em relação às estruturas evidenciou-se de forma favorável a interiorização das unidades do IFRJ, o que para os entrevistados resultou no aumento de acesso de estudantes a um ensino público de qualidade.

A verticalização também foi apontada por um dos pesquisados como um avanço dos IFs que visualiza nesta estrutura a possibilidade de constituir-se como uma instituição mais integradora, que trabalha os vários níveis e modalidades de ensino. Contudo, a verticalização foi ainda vista como um desafio ao docente no tocante à sua prática pedagógica, tendo em vista os diferentes públicos, níveis e necessidades presentes na proposta de ensino vertical, apontado como híbrido.

Somou-se à categoria dos aspectos bem vistos, o ordenamento da Lei no 11.892/2008, quanto à delimitação mínima de $50 \%$ (cinquenta por cento) de vagas destinadas à educação profissional, técnica de nível médio, preservando assim a origem e os laços culturais do IFRJ.

Incluiu-se neste bojo a determinação legal de oferecimento mínimo de $20 \%$ (vinte por cento) das vagas ofertadas pelos IFs aos cursos de licenciatura, resultando no incentivo ao fortalecimento da formação de professores. No entanto, vale destacar as dificuldades enfrentadas no oferecimento de licenciaturas em instituições sem tradição e pesquisa na área de formação docente.

Com a promulgação da Lei no. 13.0005 de junho de 2014, o Plano Nacional de Educação reitera outros desafios destinados aos IFs ampliando a sua responsabilidade para atender às legislações concernentes a todos os níveis e modalidades de ensino.

A equiparação dos IFs às Universidades Federais no tocante ao tripé ensino, pesquisa e extensão foi assinalada como um significativo avanço tendo em vista a possibilidade de pleitear junto aos órgãos de fomento, o apoio ao desenvolvimento de pesquisas. No entanto, os respondentes não se mostraram conscientes de que essa equiparação envolve, também, a avaliação dos IFs nos mesmos moldes das universidades, o que pode dificultar a avaliação dos cursos e o próprio funcionamento da instituição. 
Apesar de todas estas benesses mencionadas pelos entrevistados, houve um significativo destaque para as desvantagens destas ações governamentais no tocante à aceleração do processo de expansão da Rede Federal, que resultou na perda de identidade e de cultura das instituições que compuseram o IFRJ.

Os informantes destacaram a diminuição dos espaços pedagógicos característicos do ensino técnico que distinguiam originalmente o CEFET de Química de Nilópolis/RJ, bem como as particularidades rurais que marcavam o Colégio Agrícola Nilo Peçanha. Soma-se o relato de um dos depoentes quanto ao despreparo do IFRJ no oferecimento dos ensinos de graduação e pósgraduação, bem como no cumprimento das exigências legais pertinentes às Universidade Federais.

A aquisição de servidores administrativos proporcionou a diversificação de perfil deste extrato profissional, fazendo surgir um público mais preparado academicamente e atuante tanto nas frentes administrativas quanto pedagógicas, acenando favoravelmente ao IFRJ. $O$ ponto nevrálgico neste aspecto figura na dificuldade destes recém-ingressos em conhecer a conjuntura cultural e pedagógica da instituição e participarem desta nova reconfiguração.

Com a expansão dos campi, também foram notados e acentuados antigos problemas estruturais como o da comunicação institucional. Diante do aumento do número de servidores, da estrutura pedagógica e da dispersão geográfica, a instituição perdeu parte da proximidade da comunidade acadêmica presente na antiga estrutura de escola.

Frente aos resultados da pesquisa tornaram-se manifestas as dificuldades do IFRJ em constituir-se sem perder alguns elementos estruturantes de suas instituições originárias, causando um estranhamento cultural e de identidade. A nova organização educacional proposta, e posta em prática pelos governantes nos últimos anos, suscita a continuidade de estudos que possam investigar e refletir a respeito do processo de implantação dos IFs na prática, pois cada Instituto Federal tem uma composição diferente dos demais e, vários deles, podem estar enfrentando dificuldades que não foram exploradas neste estudo voltado para o IFRJ.

\section{REFERÊNCIAS}

1. BARDIN, L. Análise de conteúdo. Lisboa. Edições 70, 1979.

2. BELLONI, I; MAGALHÃES, H.; SOUZA. L. C. Metodologia de Avaliação em políticas públicas: uma experiência em educação profissional. São Paulo: Cortez, 2000.

3. BRASIL. Lei no 13.005, de 25 de junho de 2014. Aprova o Plano Nacional de Educação - PNE e dá outras providências. Diário Oficial [da] República Federativa do Brasil, Poder Executivo, Brasília, DF - Seção 1 - Edição Extra - 26/6/2014.

4. _. Projeto de Lei no 3.775 em julho de 2008. Institui a Rede Federal de Educação Profissional, Científica e Tecnológica, cria os Institutos Federais de Educação, Ciência e Tecnologia, e dá outras providências. Disponível em: http://www.camara.gov.br/pro posicoesWeb/fichadetramitacao?idProposicao=405479. Acesso em 08 jul. 2012.

5. _. Poder Executivo. Decreto no 7.566, de 23 de setembro de 1909. Cria nas capitais dos Estados da Republica Escolas de Aprendizes Artífices, para o ensino profissional primário e gratuito. Diário Oficial [da] República Federativa do Brasil, Rio de Janeiro, DF, Seção 1, p. 6975, 26 set 1909. 
6. .Decreto-Lei no. 8.300 de 6 de dezembro de 1945. Cria cursos técnicos na Divisão de Ensino Industrial do Departamento Nacional de Educação, e dá outras providências. Disponível em: <http://www2.camara.gov.br/legin/fed/declei/1940-1949/decreto-lei-8300-6-dezembro -1945-457490-publicacaooriginal-1- e.html>Acesso em 8 jul. 2012.

7. _. Lei no 10.861 de 14 de abril de 2004. Institui o Sistema Nacional de Avaliação da Educação Superior - SINAES e dá outras providências. Diário Oficial [da] República Federativa do Brasil, Rio de Janeiro, DF, Seção 1, p. 3, 15 abr 2004.

8. _L__Lei no 8.948, de 8 de dezembro de 1994. Dispõe sobre a instituição do Sistema Nacional de Educação Tecnológica e dá outras providências. Diário Oficial [da] República Federativa do Brasil, Rio de Janeiro, DF, Seção 1, p. 18882, 09 dez 1994.

9. .Projeto de Lei no 3.775 em julho de 2008. Institui a Rede Federal de Educação Profissional, Científica e Tecnológica, cria os Institutos Federais de Educação, Ciência e Tecnologia, e dá outras providências. Disponível em: http://www.camara.gov.br/propo sicoesWeb/fichadetramitacao?idProposicao=405479. Acesso em 08 jul. 2012.

10. Plano de Desenvolvimento Institucional - PDI, do Centro Federal de Educação Tecnológica de Química de Nilópolis referente ao ciclo (2005-2009), Nilópolis, Rio de Janeiro, 2008.

11. .Congresso Nacional. Lei no 11.892, de 29 de dezembro de 2008. Institui a Rede Federal de Educação Profissional Científica e Tecnológica e dá outras providências. Diário Oficial [da] República Federativa do Brasil, Brasília, DF, Seção 1, p. 1, 30 dez. 2008.

12. .MEC. Plano de Desenvolvimento Institucional - PDI - 2009-2013. Rio de Janeiro, IFRJ, Julho de 2009.

13. _.MEC/SETEC no 002/de 12 de dezembro de 2007. Chamada Pública de propostas para constituição dos Institutos Federais de Educação, Ciência e Tecnologia - IFET.

14. _.MEC/SETEC. Plano Pedagógico Institucional - PPI, do Instituto Federal de Educação, Ciência e Tecnologia do Rio de Janeiro. 2011. Disponível em: < http://www.ifrj.edu.br/webf m_send/491>. Acesso em 8 jul. 2012.

15. CENTRO FEDERAL DE EDUCAÇÃO TECNOLÓGICA DE QUÍMICA DE NILÓPOLIS - RJ. CPA. Relatório de Autoavaliação Institucional referente ao ciclo (2006-2008), Nilópolis, Rio de Janeiro, 2008. Disponível em: < http://ifrj.edu.br/webfm_send/487>. Acesso em 8 jul. 2012.

16. CIAVATTA, M. Universidades Tecnológicas: horizontes dos Institutos Federais de Educação, Ciência e Tecnologia (IFETS)?. In MOLL, J. e Colaboradores. Educação profissional e tecnológica no Brasil contemporâneo: desafios, tensões e possibilidades. Porto Alegre: Artmed, 2010.

17. GIL, A. C. Como elaborar projetos de pesquisa. 5. ed. São Paulo: Atlas, 2010.

18. MANFREDI, S. M. Educação profissional no Brasil. SP: Cortez, 2002.

19. LIMA FILHO, D. L. Universidade tecnológica e redefinição da institucionalidade da educação profissional: concepções e práticas em disputa. In MOLL, J. e Colaboradores. Educação profissional e tecnológica no Brasil contemporâneo: desafios, tensões e possibilidades. Porto Alegre: Artmed, 2010.

20. MILITÃO, M. N. de S. do A. Novos rumos para o ensino técnico: impactos e perspectivas - o caso do Centro Federal de Educação Tecnológica de Minas Gerais - Cefet-MG. (Tese de Doutorado). PUC, São Paulo, 1988, 244 f. 
21. OTRANTO, C. R. Criação e Implantação dos Institutos Federais de Educação, Ciência e Tecnologia - IFET's. Revista de Educação Técnica e Tecnológica em Ciências Agrícolas - RETTA - PPGEA/UFRRJ. Rio de Janeiro, Seropédica: EDUR- Editora da UFRRJ, 2010, p.p 89-110.

22. _. A política de educação profissional do governo Lula. Texto apresentado na 34ạ. Reunião Anual da ANPED, Natal, RN, 2011. 